\title{
WITHIN-PLANT VARIATION IN CONCENTRATIONS OF AMINO ACIDS, SUGAR, AND SINIGRIN IN PHLOEM SAP OF BLACK MUSTARD, Brassica nigra (L.) KOCH (CRUCIFERAE)
}

\author{
STEWART Z. MERRITT ${ }^{\prime}$ \\ Department of Biology \\ Universiry of Michigan \\ Ann Arhor, Michigan 48109-1048
}

(Recejved September 16, 1994: accepted January 30, 1996)

\begin{abstract}
Although within-plant variation in the nutrient and allelochemical composition of phloem sap has been invoked to explain pattems of host use by phloem-feeding insects, little is known about within-plant variation in phloem chemistry. Here I describe a new technique in which I use the green peach aphid. Myzus persicae Sulz, to investigate within-plant variation in the concentrations of chemicals in the phloem sap of black mustard, Brassica nigra (L.) Koch (Cruciferae). Relationships between the concentrations of chemicals in aphid diets and honeydew were established using honeydew from aphids fed on artificial diets with known concentrations of amino acids, sucrose. and sinigrin. These relationships were applied to honeydew from aphids fed on different aged leaves of black mustard to estimate the concentrations of the chemicals in phloem sap. Sinigrin concentration was estimated to be high $(>10 \mathrm{mM}$ ) in phloem sap in young leaves, calling into question the prevailing opinion that phloem sap contains only low concentrations of allelochemicals. High concentrations may function as defenses against sap-feeding herbivores. Within-plant variation in phloem sap composition was high: (1) young leaves had high concentrations of nutrients $(216 \mathrm{mM}$ amino acids, $26 \%$ sugar $)$ and sinigrin $(>10 \mathrm{mM}) ;(2)$ mature and presenescent leaves had lower concentrations of nutrients (77-83 $\mathrm{mM}$ amino acids. $19-20 \%$ sugar) and low concentrations of sinigrin (1-2 $\mathrm{mM})$; and (3) senescing leaves had high concentrations of nutrients ( $199 \mathrm{mM}$ amino acids, $25 \%$ sugar) and low concentrations of sinigrin $(3 \mathrm{mM})$.
\end{abstract}

Key Words-Mycus persicae, Brassica nigra, phloem sap. glucosinolates. sinigrin, herbivore distributions, plant defense.

'Current address: Department of Biology. University of Puget Sound, Tacoma, Washington 98416. 


\section{INTRODUCTION}

Extensive variation in the nutrient and allelochemical composition of foliage has been documented within individual plants, and this variation has been proposed to explain spatial and temporal patterns of host use by leaf-chewing insects (e.g., Feeny, 1970; Mattson, 1980; Denno and McClure, 1983). Similar arguments have been made to explain host use by phloem-feeding insects (van Emden, 1972; Dixon, 1976; Wink et al., 1982; Whitham, 1983; Wink and Römer, 1986), but almost no information is available about within-plant variability in the chemistry of phloem sap. Phloem sap contains two macronutrients, amino acids and sugars (usually sucrose). Although concentrations of these chemicals in phloem sap have been measured in many plants (e.g., Becker, 1973; and cited in Ziegler, 1975; Zimmerman and Ziegler, 1975), their variability within individual plants has been investigated in only two species: Salix acutifolia (Mittler, 1958) and Lupinus albus (Pate et al., 1979). Similarly, the presence of allelochemicals in phloem sap is now firmly established (Molyneux et al., 1990; Montllor, 1991). However, within-plant variability in the concentrations of these chemicals in phloem sap has been assessed in only one species, Lupinus consentinii (Wink et al., 1982).

A major obstacle to examining within-plant variability in the chemical composition of phloem sap has been the difficulty of obtaining phloem sap in sufficient quantity and purity for chemical analysis. For example, the method that probably yields the purest samples, the severed-stylet technique (Kennedy and Mittler, 1953), suffers from three potentially serious drawbacks (Fisher and Frame, 1984). First, not all plant species exude phloem sap through severed homopteran stylets. Second, even among those species that do, yields are generally small, especially from herbaceous plants. Third, exudation rates can vary greatly depending on tissue age. This last drawback is especially serious, for if parts of a plant cannot be sampled, within-plant variability cannot be meaningfully assessed.

Here I present a new technique for estimating the composition of phloem sap from aphid honeydew. This technique is used to examine the exposure of the green peach aphid, Myzus persicae Sulz., to nutrients and allelochemicals in phloem sap of different aged leaves of black mustard, Brassica nigra (L.) Koch (Cruciferae). The green peach aphid is a polyphagous herbivore that feeds on phloem sap (Pollard, 1973; but see van Emdem et al., 1969), and black mustard is one of the aphid's host plants. The phloem sap of crucifers contains amino acids (Pate, 1973) and glucosinolates (Weber et al., 1986), a class of sulfur-containing allelochemicals. Natural populations of the aphid on crucifers occur mainly on the lower, senescing leaves of the plants (van Emden et al., 1969), and it has been hypothesized that this pattern results from within-plant 
differences in the nutrient and allelochemical composition of phloem sap (van Emden, 1972).

\section{METHODS AND MATERIALS}

Aphids. Two clones of the green peach aphid were used. One was initiated from a single asexually reproducing female (virginopara) obtained from a greenhouse population feeding on tree tomato (Cyphomandra crassicaulis, Solanaceae) at the University of Michigan Matthaei Botanical Gardens. The clone was maintained for two years in the laboratory on radish seedlings (var. Red Devil B, Ferry-Morse Seed Co., Modesto, California) at room temperature under long day conditions (18L:6D). Voucher specimens are deposited at the Illinois State Natural History Survey, Champaign, Illinois. A second clone was obtained from a laboratory culture at the University of California at Berkeley, where it had been maintained for many years on radish (T. E. Mittler, personal communication.)

Honeydew Collection from Aphids Fed on Artificial Diets. I used chemically defined liquid diets developed for the green peach aphid (Kunkel, 1977; diet a) modified for a three-way factorial design with two levels of the amino acid mixture $(61$ and $122 \mathrm{mM})$, two levels of sucrose $(10 \%$ and $20 \%)$, and three levels of sinigrin (Sigma) $(0,5$, and $10 \mathrm{mM})$. These amino acid and sucrose concentrations were within the range of values recorded in the phloem sap of herbaceous plants (Barlow and Randolph, 1978; Fukumorita and Chino, 1982; Chino et al., 1986; Hayashi and Chino, 1986; Fisher and Gifford, 1986). Because no data on sinigrin concentrations in phloem sap were available, sinigrin concentrations were based on assays of tissue homogenates of black mustard (Feeny and Rosenberry, 1982). Sinigrin was the only glucosinolate in the present study to be detected by GLC in the honeydew of aphids feeding on black mustard (S. Merritt, unpublished data). This experiment was conducted using the University of Michigan clone.

I conducted a subsequent experiment to extend the range of amino acid concentrations present in the diet. This second experiment used the University of Califomia clone because the University of Michigan clone was no longer available. The experiment was a one-way design with three levels of the amino acid mixture $(92,184$, and $276 \mathrm{mM})$ and constant levels of sucrose $(15 \%)$ and sinigrin $(0 \%)$.

Diets were prepared according to Kunkel (1977), filtered $(0.45 \mu \mathrm{m})$ into sterile plastic vials under a laminar-flow hood, and stored at $-60^{\circ} \mathrm{C}$ until needed. All diets were used within 14 days of mixing.

Diets were offered in Parafilm sachets consisting of about $0.2 \mathrm{ml}$ of diet 
sandwiched between two layers of stretched Parafilm (Mittler and Dadd, 1964). To minimize microbial contamination, sachets were prepared according to published procedures (Kunkel, 1977) with two modifications. First, sachets were prepared under a laminar-flow hood with diets dispensed from sterile glass pipets. Second, the Parafilm was not surface sterilized. Instead, only the paper-covered side of the Parafilm was allowed to contact the diet (i.e., form the inside of the sachet).

Aphids were reared in cages in an incubator $\left(21^{\circ} \mathrm{C}, 16 \mathrm{~L}: 8 \mathrm{D}\right)$ for five days. Cages were made from $3-\mathrm{cm}$ segments of acrylic tubing $(3.81 \mathrm{~cm}$ OD, $3.18 \mathrm{~cm}$ ID) covered with a Parafilm sachet on the top and plastic cap on the bottom. Aphids fed upside down by piercing the Parafilm membrane and imbibing the liquid diet. Aphids were transferred to cages with fresh sachets every three days.

Each cage was started with five adult aphids that were allowed to feed and reproduce for five days, after which honeydew collection began. To collect honeydew, the bottom of each cage was removed, and the cage was nested in a $50-\mathrm{ml}$ polypropylene beaker containing about $20 \mathrm{ml}$ of technical grade ( $94 \%$ ) 1 -hexadecene ( $\mathrm{mp}, 4^{\circ} \mathrm{C} ; \mathrm{bp}, 274^{\circ} \mathrm{C}$ ) (Aldrich). Honeydew excreted by the aphids fell into the 1-hexadecene in the beaker and accumulated below the surface, which prevented honeydew evaporation so that solute concentrations could be measured. Honeydew from each cage was removed daily with a plastic micropipet tip, pooled with honeydew collected previously from the same cage, and stored under 1-hexadecene at $-60^{\circ} \mathrm{C}$ until chemical analysis. About $0.1-0.2$ $\mathrm{ml}$ of honeydew was recovered from each cage in six days of collection.

Honeydew Collection from Aphids Fed on Black Mustard. Black mustard plants were grown from seed (obtained from V \& J Seed Farms, Woodstock, Illinois) under natural light from December to March in a greenhouse at the University of Michigan Matthaei Botanical Gardens. Plants were grown individually in 20.3-cm pots in potting soil (Fison's Sunshine Mix No. 4), watered daily, and fertilized every two weeks. After the plants had bolted, aphids were placed on leaves of four developmental stages on each plant: (1) young actively growing leaves; (2) mature leaves (dark green); (3) presenescent leaves (light green); and (4) senescent leaves (yellow-green to yellow). To collect honeydew, a plastic cup containing 1-hexadecene was positioned under each aphid-infested leaf. Each cup was supported by an acrylic ring that was attached to a ring stand by a steel rod. Honeydew from each leaf was collected as described above, pooled with honeydew collected previously from the same leaf, and stored under 1-hexadecene at $-20^{\circ} \mathrm{C}$ until chemical analysis. About $0.2-0.3 \mathrm{ml}$ of honeydew was recovered from each leaf in seven days of collection.

Chemical Analysis of Honeydew. The amino acid concentration in honeydew was measured colorimetrically (Coleman Junior Spectrophotometer, model 6C; or Sequoia-Tumer, model 340) by the ninhydrin method (Spies, 1957). Concentrations were expressed in asparagine equivalents because asparagine was 
the dominant amino acid in the artificial diets (Kunkel, 1977) and is often present in high concentration relative to other amino acids in the phloem sap of herbaceous plants (e.g., Pate et al., 1974; Barlow and Randolph, 1978; Fukumorita and Chino, 1982; Wink and Witte, 1984; Hayashi and Chino, 1986).

The sugar concentration in honeydew was measured colorimetrically (Coleman Junior Spectrophotometer, model 6C) by the phenol-sulfuric acid method (Hodge and Hofreiter, 1962). Sugar concentrations were expressed in sucrose equivalents because sucrose was the sugar in the artificial diets (Kunkel, 1977) and is the dominant carbohydrate in the phloem sap of herbaceous plants (e.g., Pate et al., 1974; Barlow and Randolph, 1978; Fukumorita and Chino, 1982; Hayashi and Chino, 1986), including crucifers (Pate, 1973).

Glucosinolate concentrations in honeydew were measured by gas chromatography (GC) of isothiocyanate hydrolysis products following the procedures of Rodman (1978) and Blau and Hanscom (1986). Phosphate buffer, ascorbate, and myrosinase were prepared according to Rodman (1978). Measured honeydew samples $(0.025-0.125 \mathrm{ml})$ were placed into $1 / 2$-dram shell vials along with phosphate buffer $(0.450 \mathrm{ml})$, ascorbate solution $(0.020 \mathrm{ml})$, myrosinase extract $(0.010 \mathrm{ml})$, and methylene chloride $(0.500 \mathrm{ml})$, which contained $0.01 \% \mathrm{n}$ undecane as an internal standard. Vials were capped and shaken gently at room temperature for $12 \mathrm{hr}$, after which the methylene chloride phase, without concentration. was subjected to analysis on a Hewlett-Packard 5890 gas chromatograph furnished with a $30-\mathrm{m}$ column coated with a $100 \%$ methyl polysiloxane stationary phase. Both injector and FID temperatures were $250^{\circ} \mathrm{C}$. Oven temperature was maintained at $90^{\circ} \mathrm{C}$ for $1 \mathrm{~min}$ and then increased at $50^{\circ} \mathrm{C} / \mathrm{min}$. Glucosinolates were identified and quantified by comparing retention times and peak areas with standards. Identifications were confirmed by GC-MS. Up to 75 samples per day were analyzed following this procedure.

Mean extraction efficiency of sinigrin standards was $80.6 \%$ ( $S D=10.9 \%$. $N=35$ ). To avoid underestimating sinigrin concentrations in honeydew, estimates were based on a standard curve.

Statistical Analysis. All statistical analyses were done using SYSTAT (Wilkinson, 1990). Stepwise multiple linear regression was performed on various combinations of the independent variables (i.e., concentrations of chemicals in the honeydew), both transformed and untransformed, to generate equations for estimating concentrations of amino acids, sugar, and sinigrin in artificial diets from concentrations of these chemicals in aphid honeydew. These regressions are for predictive purposes only and are not meant to characterize mechanistic relationships. Ideally, a range of concentrations of diet components should be used to reliably characterize the relationship between aphid diets and honeydew. However, because the experiment was a factorial design, only two or three levels of diet components were feasible. As a result, some precision will be lost when estimating the concentrations of chemicals in phloem sap using these 
equations. Furthermore, estimated concentration of sinigrin in young leaves was far higher than the highest diet concentration used to generate the equations; therefore, the highest diet concentration is presented as a conservative estimate of the concentration present, assuming a monotonically increasing relationship.

Estimated concentrations of amino acids in phloem sap were log transformed to obtain homogeneous variances, after which pairwise comparisons were made using a Tukey HSD test. Variances in the estimated concentrations of sugars in phloem sap could not be made homogeneous, so pairwise comparisons were made using Mann-Whitney $U$ tests with alpha adjusted to 0.008 $(0.05 / 6)$ for multiple comparisons.

Pairwise comparisons of means for estimated levels of sinigrin were tested using two-sample $t$ tests when both values were within the range of diet concentrations used to generate the equations. When one of the values has higher than the highest diet concentration used, comparisons were done using onesample t tests with the highest diet concentration $(10 \mathrm{mM})$ used as the known mean. Estimated concentrations of sinigrin in the phloem sap of mature, presenescent, and senescing leaves were $\log (X+1)$ transformed to satisfy the assumptions of normality and homogeneity of variance. Alpha was adjusted to $0.008(0.05 / 6)$ for multiple comparisons.

\section{RESULTS}

To estimate the composition of diets from the composition of honeydew, the following equations were generated relating the concentrations of amino acids (AA), sugar (SU), and sinigrin (SI) measured in the honeydew (h) of aphids fed on artificial diets (hAA, hSU, hSI, respectively) with the dietary (d) concentrations of these chemicals (dAA, dSU, dSI) (Table 1). In the parentheses below each equation is the range of concentrations in the diet component over which these equations apply and the proportion of the variance in the diet component explained by the equations (i.e., $r^{2}$ ).

$d A A[\mathrm{mM}]=24.6+28.3(h A A[\mathrm{mM}])^{1 / 2}$

(range: $61-276 \mathrm{mM} ; r^{2}=0.968$ )

$$
\begin{gathered}
d S U[\%]=-4.05+4.59(h S U[\%])^{1 / 2}+1.81(h A A[\mathrm{mM}])^{1 / 2} \\
\left(\text { range: } 10-20 \% ; r^{2}=0.961\right) \\
d S I[\mathrm{mM}]=0.438+0.405(h S I[\mathrm{mM}])(h S U[\mathrm{mM}])^{1 / 2}
\end{gathered}
$$$$
\text { (range: } 0-10 \mathrm{mM} ; r^{2}=0.940 \text { ) }
$$ 
Table 1. Concentrations of Amino Acids, Sugars, and Sinigrin in Honeydew from Aphids Fed on ARtificial Diets

\begin{tabular}{|c|c|c|c|c|c|}
\hline \multicolumn{3}{|c|}{ Diet concentration } & \multicolumn{3}{|c|}{ Honeydew concentration (mean $\pm \mathrm{SEM})^{a}$} \\
\hline $\begin{array}{l}\text { Amino acids } \\
(\mathrm{mM})\end{array}$ & $\begin{array}{c}\text { Sucrose } \\
(\%)\end{array}$ & $\begin{array}{l}\text { Sinigrin } \\
(\mathrm{mM})\end{array}$ & $\begin{array}{l}\text { Amino acids } \\
(\mathrm{mM})^{i}\end{array}$ & $\begin{array}{l}\text { Sugars } \\
(\%)^{r}\end{array}$ & $\begin{array}{l}\text { Sinigrin } \\
(\mathrm{mM})\end{array}$ \\
\hline \multirow[t]{6}{*}{61} & \multirow[t]{3}{*}{10} & 0 & $1.74 \pm 0.062$ & $6.38 \pm 0.288$ & $0.00 \pm 0.000$ \\
\hline & & 5 & $1.82 \pm 0.046$ & $6.58 \pm 0.151$ & $4.19 \pm 0.141$ \\
\hline & & 10 & $2.31 \pm 0.072$ & $7.23 \pm 0.181$ & $8.86 \pm 0.533$ \\
\hline & \multirow[t]{3}{*}{20} & 0 & $2.09 \pm 0.062$ & $21.10 \pm 0.960$ & $0.00 \pm 0.000$ \\
\hline & & 5 & $2.61 \pm 0.059$ & $19.47 \pm 0.669$ & $2.20 \pm 0.068$ \\
\hline & & 10 & $2.66 \pm 0.090$ & $22.08 \pm 0.690$ & $4.57 \pm 0.215$ \\
\hline 92 & 15 & 0 & $6.24 \pm 0.189$ & ND & ND \\
\hline \multirow[t]{6}{*}{122} & \multirow[t]{3}{*}{10} & 0 & $12.45 \pm 0.485$ & $3.01 \pm 0.114$ & $0.00 \pm 0.000$ \\
\hline & & 5 & $12.43 \pm 0.337$ & $2.78 \pm 0.171$ & $6.68 \pm 0.240$ \\
\hline & & 10 & $11.85 \pm 0.427$ & $2.83 \pm 0.082$ & $13.62 \pm 0.587$ \\
\hline & \multirow[t]{3}{*}{20} & 0 & $9.92 \pm 0.223$ & $15.62 \pm 0.447$ & $0.00 \pm 0.000$ \\
\hline & & 5 & $8.90 \pm 0.169$ & $15.95 \pm 0.348$ & $2.73 \pm 0.129$ \\
\hline & & 10 & $9.50 \pm 0.225$ & $16.78 \pm 0.849$ & $6.05 \pm 0.338$ \\
\hline 184 & 15 & 0 & $24.56 \pm 0.498$ & ND & ND \\
\hline 276 & 15 & 0 & $88.02 \pm 2.656$ & ND & ND \\
\hline
\end{tabular}

"Sample size $=10$ for all means. ND, not determined.

"Asparagine equivalents.

"Sucrose equivalents.

Table 2. Concentrations of Amino Acids, Sugars, and Sinigrin in Honeydew From ApHids Fed on Leaves of Black MUSTaRd

\begin{tabular}{lcccr} 
& \multicolumn{4}{c}{ Honeydew concentration (mean \pm SEM) } \\
\cline { 2 - 5 } \multicolumn{1}{c}{ Leaf age } & $\begin{array}{c}\text { Amino acids } \\
(\mathrm{mM})^{\circ}\end{array}$ & $\begin{array}{c}\text { Sugars } \\
(\%)^{\prime \prime}\end{array}$ & $\begin{array}{c}\text { Sinigrin } \\
(\mathrm{mM})\end{array}$ & $N$ \\
\hline Young & $56.1 \pm 11.99$ & $13.7 \pm 0.77$ & $15.41 \pm 2.040$ & 9 \\
Mature & $5.2 \pm 1.52$ & $18.9 \pm 0.81$ & $0.74 \pm 0.131$ & 10 \\
Presenescent & $3.7 \pm 0.56$ & $18.7 \pm 0.69$ & $0.34 \pm 0.104$ & 10 \\
Senescent & $52.6 \pm 13.97$ & $14.2 \pm 1.54$ & $2.17 \pm 0.624$ & 10 \\
& & & & \\
\hline
\end{tabular}

\footnotetext{
"Asparagine equivalents.

"Sucrose equivalents.
} 
Table 3. Estimated Concentrations of Amino Acids, Sugars, and Sinigrin in Phloem Sap of Black Mustard

\begin{tabular}{lcccr}
\hline & \multicolumn{4}{c}{ Estimated Honeydew Concentration (mean and $95 \% \mathrm{Cl})^{a}$} \\
\cline { 2 - 5 } Leaf age & $\begin{array}{c}\text { Amino acids } \\
(\mathrm{mM})^{b}\end{array}$ & $\begin{array}{c}\text { Sugars } \\
(\%)^{r}\end{array}$ & $\begin{array}{c}\text { Sinigrin } \\
(\mathrm{mM})^{d}\end{array}$ & $N$ \\
\hline Young & $215.7 \mathrm{a}$ & $25.8 \mathrm{a}$ & $>10.00 \mathrm{a}$ & 9 \\
Mature & $(167.5-277.8)$ & $(23.0-28.6)$ & & 10 \\
Presenescent & $83.4 \mathrm{~b}$ & $19.8 \mathrm{~b}$ & $1.66 \mathrm{bc}$ & 10 \\
Senescing & $(71.3-97.6)$ & $(19.0-20.5)$ & $(1.13-2.32)$ & 10 \\
& $77.0 \mathrm{~b}$ & $19.2 \mathrm{~b}$ & $0.96 \mathrm{c}$ & 10 \\
& $(69.1-85.9)$ & $(18.4-20.0)$ & $(0.58-1.43)$ & $3.02 \mathrm{~b}$ \\
& $198.5 \mathrm{a}$ & $25.1 \mathrm{a}$ & $(1.75-4.88)$ & \\
\hline
\end{tabular}

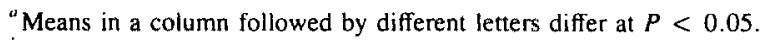

${ }^{b}$ Asparagine equivalents back-transformed from $\log (X)$.

'Sucrose equivalents.

${ }^{d}$ Back-transformed from $\log (X+1)$. Estimates for sinigrin in young leaves were far higher than the highest diet concentration used to generate the equations; therefore, the highest diet concentration is presented as a conservative estimate of the concentration present, assuming a monotonically increasing relationship.
}

Applying these equations to the concentrations of chemicals measured in honeydew of aphids fed on black mustard (Table 2) gave estimates of the concentrations of chemicals in phloem sap (Table 3). Phloem sap in young and senescing leaves contained higher amino acid and sugar concentrations than phloem sap in mature and presenescent leaves. A high concentration of sinigrin occurred only in phloem sap in young leaves. Although the concentration of sinigrin was slightly higher in phloem sap in senescing leaves than in mature and presenescent leaves, sinigrin concentrations in these leaves were far lower than those in young leaves.

Based on the nutrient and allelochemical profile of their phloem sap, leaves of black mustard fell into three classes: (1) young leaves with high concentrations of nutrients and sinigrin, (2) mature and presenescent leaves with low concentrations of nutrients and sinigrin, and (3) sensecing leaves with high concentrations of nutrients and low concentrations of sinigrin.

\section{DISCUSSION}

The conclusions of this study rest on the reliability of the estimate of phloem sap composition. Two lines of evidence suggest that the estimates are reasonable. First, the artificial diet experiment shows that diet composition can 
be accurately estimated from honeydew composition. Indeed, the regressions explained $94 \%$ or more of the variance in diet concentrations of amino acids, sucrose, and sinigrin. Second, the estimates in the present study compare favorably with values obtained in other studies. The estimated concentrations of amino acids in the phloem sap of black mustard (77-216 mM) (Table 3) are similar to those measured in the phloem sap of a variety of herbaceous plant species (112-1600 mM) (Barlow and Randolph, 1978; Fukumorita and Chino, 1982; Pate et al., 1984; Fisher and Gifford, 1986; Weibull. 1988). Similarly, estimated sugar concentrations (19.1-25.8\%) (Table 3) fall within the range recorded in herbaceous plants (4.3-30.8\%) (e.g., Pate, 1973; Pate et al., 1974; Fukumorita and Chino, 1982; Fisher and Gifford, 1986; Ohshima et al., 1990). However, feeding by aphids has been shown to enhance the translocation of sugars into infested leaves, and thus it is possible that these estimates are high (Way and Cammell. 1970).

Nevertheless, there remains some concem about the accuracy of the estimates of phloem sap composition both because the equations are based on very few levels of diet components and because some estimates fall far outside the range of concentrations over which the equations apply. In addition, the estimation procedure is sensitive to the presence of nontarget compounds that give positive reactions with the assays. This latter consideration is unlikely to be important for sinigrin because of the high specificity of the GC test for this chemical. However, the ninhydrin and phenol-sulfuric acid assays are not as specific, and it is known that phloem sap contains a number of chemicals that give positive reactions with each (e.g., nonprotein amino acids, nucleotides for ninhydrin assay; flavonoids, phenolics, complex carbohydrates for phenol-sulfuric assay). The estimation procedure assumes the presence of insignificant amounts of these interfering chemicals, and estimates will be inflated depending on the levels of these chemicals in the phloem sap and their metabolism in the gut of aphids.

It is generally believed that phloem sap contains only low concentrations of allelochemicals (Mullin, 1986; Dreyer and Campbell, 1987; Klingauf, 1987a; Brattsten, 1988). However, the estimates in this study of the concentrations of sinigrin in phloem sap in young leaves $(>10.00 \mathrm{mM}$, i.e., $>0.416 \%$ fresh weight) are as high as those measured in foliage of black mustard $(0.165-$ $0.632 \%$ fresh weight) (Feeny and Rosenberry, 1982). Indeed, the sinigrin concentration in phloem sap in young leaves might be even higher because the highest diet concentration is presented as a conservative estimate of the concentration present. Thus, the present study adds to the growing body of evidence documenting high concentrations of allelochemicals in phloem sap (Wink et al., 1982; Wink and Witte, 1984) and in related vascular exudates (Treutter et al., 1985; Niemeyer, 1988; Peng and Miles, 1991).

The assumption that allelochemicals occur at low concentrations in phloem 
sap has led many authors to conclude that phloem-borne allelochemicals do not act as defenses against sap-feeders (Mullin, 1986: Dreyer and Campbell, 1987; Klingauf, 1987a; Brattsten, 1988). However, the presence of high allelochemical concentrations indicates that this conclusion needs to be reconsidered. Furthermore, the occurrence of within-plant variability in allelochemical concentrations in phloem sap suggests that some plant parts may be better defended than others. For example, the high sinigrin concentration in young leaves implies that they will be better defended against nonadapted sap-feeding herbivores than will mature, presenescent, or senescent leaves. Similar withinplant variability was also documented in a species of lupine. Lupinus consentinii. in which it was found that phloem sap from fruits contained over three times the alkaloid concentration as phloem sap in stems (Wink et al., 1982). These data support the hypothesis that young leaves should be better defended against herbivores because they have higher relative fitness value to the plant than do mature, presenescent, and senescing leaves (McKey, 1979; Rhoades, 1979).

Nutrient concentrations in phloem sap also varied within plants. Young and senescent leaves of black mustard contained higher amino nitrogen and sugar than did mature and presenescent leaves (Table 3). Similar patterns have been reported for nitrogen in phloem sap. Phloem sap in young and senescing foliage of Salix acutifolia contains about three times the nitrogen as phloem sap of mature foliage (Mittler, 1958). Likewise, phloem exudate from growing tissue (stem tops, developing fruits) of Lupinus albus contains about 1.7 times the amino nitrogen as exudate from mature leaves (Pate et al., 1979). Moreover, as mature leaves senesce, amino nitrogen content increases 1.7 times (Pate et al. 1979). This pattern of high amino nitrogen concentration in phloem in senescing leaves probably arises from the breakdown of leaf proteins and subsequent translocation back to the plant of the resulting amino acid components prior to leaf abscission (Stoddart and Thomas, 1982). Pate et al. (1979) also examined within-plant variation in sucrose concentrations. In contrast to the present study, concentrations in exudate from growing tissue of Lupinus albus were lower $(0.7-$ 0.8 times) than in exudate from mature leaves.

The within-plant variability in phloem sap composition documented here may affect the performance and feeding preferences of sap-feeding herbivores. Numerous studies have shown that variation in dietary concentrations of amino acids and sucrose affects aphid growth, survival, and reproduction (reviewed in Klingauf, 1987a). Allelochemicals too can alter food quality for aphids, acting as arrestants, deterrents, or phagostimulants (see references in Klingauf. 1987b; Risebrow and Dixon, 1987; Montllor, 1991). In plants, variability in these chemicals will make some feeding sites more suitable than others. For example, by feeding on senescing leaves of black mustard, a phloem-feeding insect would simultaneously maximize its nutrient intake and minimize its exposure to sinigrin. This explanation appears to account for the occurrence of highest densities 
of the green peach aphid on senescing leaves of crucifers (van Emden et al. 1969). Within-plant variation in phloem chemistry may similarly explain some of the patterns of host use seen in other phloem-feeding insects (Dixon, 1976; Wink et al. 1982; Whitham, 1983; Wink and Römer, 1986).

Acknowledyments-1 thank T. Mittler for providing a clone of aphids and D. Vengtlin for identifying them. I also thank C. Bach, G. Estabrook, H. Kirkpatrick, M. Martin, B. Rathcke, and one anonymous reviewer for insightful criticism of this manuscript, and $P$. Knochel lor the use of the gas chromalograph. Partial funding for this research was provided by a Sigma Xi Grant-in-Aidof-Research and by the University of Michigan Rackham School of Graduate Studies.

\section{REFERENCES}

Barlow. C. A., and RandolPh, P. A. 1978. Quality and quantity of plant sap available to the pea aphid. Amm. Entmol. Soc. Am. 71:46-48.

BtckF, D. 1973. Beiträge zur Kenntnis der biochemischen Leistung pflanzlicher Assimilatlietbahnen. Dissertation Technical University. Munich.

Bl.ALI, M. J., and HANSCOM. 7.., III. 1986. Isolation and characterization of glucocapparin in Isomeris arborea Nutt. J. Chem. Ecol. 12:1449-1458.

BrATTSTEN. L. B. 1988. Enzymatic adaptations in leaf-feeding insects to host-plant allelochemicals. J. Chem. E(o)l. 14:1919-1939.

Chino, M. Hayshi, H. and Fukumortta. T. 1986. Cation and anion composition of rice phloem sap. pp. 463-464, in J. Cronshaw, W. J. Lucas, and R. T. Giaquinta (eds.). Phloem Transpont. Alan R. Liss, New York.

DFnno, R. F., and MCCLuRf, M. S. 1983. Variable Plants and Herbivores in Natural and Managed Systems. Academic Press, New York.

Dixon, A. F. G. 1976. Factors detemining the distribution of sycamore aphids on sycamore leaves during summer. Ecol. Entomol. 1:275-278.

Drtier, D. L.. and CAMPBFl.t. B. C. 1987. Chemical basis of host-plant resistance to aphids. Plant Cell Environ. 10:353-361.

FFENY, P. P. 1970. Seasonal changes in oak leaf tannins and nutrients as a cause of spring feeding by winter moth caterpillars. Ecology 51:565-581.

Ffeny, P., and Rosfenberry, L. 1982. Seasonal variation in the glucosinolate content of North American Brassica nigra and Dentaria species. Biochem. Syst. Ecol. 10:23-32.

Fisher, D. B.. and Frame, J. M. 1984. A guide to the use of the exuding-stylet technique in phloem physiology. Plama 161:385-393.

FiSHER, D. B., and GIFFORD, R. M. 1986. Accumulation and conversion of sugars by developing wheat grains. VI. Gradients along the transport pathway from the peduncle to the endosperm Cavity during grain filling. Plant Physiol. 82:1024-1030.

Fuklimorita, T., and Chino, M. 1982. Sugar, amino acid and innrganic contents in rice phloem sap. Plant Cell Physiol. 23:273-283.

HAYASHI. H., and CHINO, M. 1986. Collection of pure phloem sap from wheat and its chemical composition. Plam Cell Physiol. 27:1387-1393.

HODGE, J. E., and Hofreiter. B. T. 1962. Determination of reducing sugars and carbohydrates, pp. 380-394, in R. L. Whistler and M. L. Wolfrom (eds.). Methods in Carbohydrate Chemistry, Vol 1. Analysis and Preparation of Sugars. Academic Press, New York.

KENNEDY. J. S., and MitTLER, T. E. 1953. A method of obtaining phloem sap via the mouth-parts of aphids. Nanure 171:528 
KLINGAuF, F. A. 1987a. Feeding, adaptation and excretion. pp. 225-253, in A. K. Minks and P. Harrewijn (eds.). Aphids: Their Biology. Natural Enemies and Control, Vol. 2A. Elsevier. New York.

KunganuF, F. A. 1987b. Host plant finding and acceptance, Pp. 209-223. in A. K. Minks and P. Harrewijn (eds.). Aphids: Their Biology. Nalural Enemies and Control, Vol. 2A. Elsevier. New York.

KUnkel, H. 1977. Membrane feeding systems in aphid research. pp. 311-338, in K. F. Harris and

K. Maramorosch (eds.). Aphids as Virus Vectors. Academic Press. New York.

MATTSON. W. J. 1980. Herbivory in relation to plant nitrogen content. Almu. Rat. Eeol. Sywt. 11:119-161.

MCKFY. D. 1979. The distritution of secondary compounds within plants, pp. 55-133. in G. A. Rosenthal and D. H. Janzen (eds.). Herbivores: Their Interaction with Secondary Plant Metabolites. Academic Press. New York.

Mrtregr. T. E. 1958. Studies of the leeding and nutrition of Tuborslachus salighus (Gmelin) (Homoptera. Aphididac). II. The nitrogen and sugar composition of ingested phloem sap and excreted honeydew. J. Exp. Biol. 35:74-84.

MitrLer. T. E., and DADD. R. H. 1964. An improved method for feeding aphids on artificial diets. Ann. Entomol. Soc. An, 57:139-140.

MolyneuX, R. J., CAMpBFlL, B. C., and Drfyer, D. L. 1990 . Honeydew analysis for detecting phloem transport of plant natural products: Implications for host-plant resistance to sap-sucking insects. J. Chem. Ean. 16:1899-1909.

Montllor, C. B. 1991. The influence of plant chemistry on aphid feeding behavior, pp. 125-173, in E. Bemays (ed.). Insect-Plant Interactions. Vol. III. CRC Press. Boca Raton, Florida.

MuLLIN, C. A. 1986. Adaptive divergence of chewing and sucking arthropods to plant allelochemicals, pp. 175-209, in L. B. Brattsten and S. Ahmad (eds.). Molecular Aspects of Insect-Plant Associations. Plenum Press. New York.

NIEMEYER, H. M. 1988. Hydroxamic acids (4-hydroxy-1.4-benzoxazin-3-ones), defence chemicals in the Graminae. Phyochemistry 27:3349-3358.

OhShima, T. HAYASH, H., and Chino. M. 1990. Collection and chemical composition of pure phloem sap from Zea mays L. Plant Cell Physiol. 31:735-737.

PATE. J. S. 1973. Uptake, assimilation and transport of nitrogen compounds by plants, Soil Biol. Biochem. 5:109-119.

Pate, J. S., Sharkey, P. J., and Lewis, O. A. M. 1974. Phloem bleeding from legume fnits-a technique for study of fruit nutrition. Planta 120:229-243,

Pate, J. S.. Atkins, C. A., Hamel, K., McNeil, D. L., and Layzell, D. B. 1979. Transport of organic solutes in phloem and xylem of a nodulated legume. Plant Physiol. 63:1082-1088.

Pate, J. S. Peoples, M. B., and Atkins, C. A. 1984. Spontaneous phloem bleeding from cryopunctured fruits of the ureide-producing legume. Plant Physiol. 74:499-505.

PEng, Z., and Miles, P. W. 1991. Oxidases in the gut of an aphid. Macrosiphon rosae (L.) and their relation to dietary phenolics. J. Insect Physiol. 37:779-787.

POLLARD, D. G. 1973. Plant penetration by feeding aphids (Hemiptera, Aphidoidea): A review. Bull. Entomol. Res. 62:631-714.

RHOAdES, D. F. 1979. Evolution of plant chemical defense against herbivores, pp. 3-54, in G. A. Rosenthal and D. H. Janzen (eds.). Herbivores: Their Interaction with Secondary Plant Metabolites. Academic Press. New York.

Risebrow, A., and Dixon, A. F. G. 1987. Nutritional ecology of phloem-feeding insects, pp. 421448, in F. Slansky. Jr., and J. G. Rodgriguez (eds.). Nutritional Ecology of Insects, Mites. Spiders, and Related Invertebrates. John Wiley \& Sons, New York.

RODMAN, J. E. 1978. Glucosinolates, methods of analysis and some chemosystematic problems. Phyrochem. Bull. 11:6-31. 
SPtEs. J. R. 1957. Colorimetric procedures for anino acids. pp. 467-477, in S. P. Colowick and N. O. Kaplan (eds.). Methods in Enzymology, Vol III. Academic Press, New York.

Stoddart, J. L., and Thomas, H. 1982. Leaf senescence, pp. 592-636, in D. Boutter and B. Parthier (eds.). Nucleic Acids and Proteins in Plants: Structure, Biochemistry, and Physiology of Proteins. Springer-Verlag. New York.

Treutter. D.. Galensa, R.. Feucht, W.. and Schmid, P. P. S. 1985. Flavanone glucosides in callus and phloem of Prinus awim: Identification and stimulation of their synthesis. Phwial. Plant. 65:95-101.

VAN EMDEN, H. F. 1972. Aphids as phytochemists, pp. 25-43, in J. B. Harborne (ed.). Phytochemical Ecology. Academic Press. New York.

van Emden. H. F., Eastop. V. F., Hughes, R. D., and WaY, M. J. 1969. The ecology of Myzus persicat. Annu. Rev: Entomol. 14:197-270.

WAY, M. J., and CAMmFLL, M. 1970. Aggregation behaviour in relation to food utilizalion by aphids. pp. 229-247, in A. Watson (ed.). Animal Populations in Relation to Their Food Resources. The British Ecological Society Symposium Number 10. Blackwell Scientific Publications. Oxford.

Weber, G. Oswald, S., and Zollnfr. U. 1986. Die Winseignung von Rapssonen unterschiedichen Glucosinolatgehaltes tür Breviceryne brassicte (L.) und Mras persicte (Sulzer) (Homoptera, Aphididae). Z. Pflanzenkr. Pflanzenschutz 93:113-124.

Welbull. J. H. W. 1988. Free amino acids in the phloem sap from oats and barley resistant to Rhopalosiphum padi. Phyochemistry 27:2069-2072.

WhIthaM. T. G. 1983. Hust manipulation of parasites: Within-plant variation as a defense against rapidly evolving pests, pp. 15-41, in R. F. Denno and M. S. McClure (eds.). Variable Plants and Herbivores in Natural and Managed Systems. Academic Press, New York.

WILKINSON. L. 1990. SYSTAT: The system for statistics. SYSTAT, Inc., Evanston, Illinois

Wink. M. and RÖMER. P. 1986. Acquired toxicity-the advantages of specializing on alkaloid-rich lupines to Marrosiphom albifroms (Aphidae). Narumissenschafien 73:210-212.

WiNk, M., and WITTE, L. 1984. Tumover and transport of quinolizidine alkaloids. Diumal fuctuations of lupanine in phloem sap, leaves and fruits of Lupimus albus L. Plama 161:519-524.

Wink M. . HARTMAnN. T., Witte, L., and RHFinheImer. J. 1982. Intertelationship between quinolizidine alkaloid producing legumes and infesting insects: Exploitation of the alkaloid-containing phloem sap of Cytisus scoparius by the broom aphid Aphis cyisorum. Z. Naturforsch. $37 \mathrm{c}: 1081-1086$.

Ziegler, H. 1975. Nature of transported substances, pp. 59-100, in M. H. Zimmerman and J. A. Milbum (eds.). Encyclopedia of Plant Physiology, New Series, Vol. I. Transport in Plants. 1. Phloem Transport. Springer-Verlag, Berlin.

Zimmerman, M. H., and ZIEGLer, H. 1975. Appendix. III: List of sugars and sugar alcohols in sieve-tube exudates, pp. 480-503, in M. H. Zimmerman and J. A. Milbum (eds.). Encyclopedia of Plant Physiology. New Series, Vol. 1. Transpon in Plants. 1. Phloem Transport. Springer-Verlag, Berlin. 